\title{
Regulação hídrica entre frutos e sementes de pau-brasil durante sua maturação
}

Recebido: 28.12.2019; aceito: 27.05.2020

Como citar: Borges, I.F., Figueiredo-Ribeiro, R.C.L. \& Barbedo, C.J. 2020. Regulação hídrica entre frutos e sementes de pau-brasil durante sua maturação. Hoehnea 47: e1142019. http://dx.doi.org/10.1590/2236-8906-114/2019

\begin{abstract}
Water regulation between fruits and seeds of brazilwood during their ripening). Brazilwood, Paubrasilia echinata E.Gagnon, H.C.Lima \& G.P.Lewis, is one of the most important plant species in Brazil. Several factors may interfere in the maintenance of both seed viability and seed storage conservation, mainly its initial physiological quality. Among other factors, the quality of the seed depends on the maturation stage, being important to identify the physiological maturity to determine the best time for harvesting. The present work describes changes during the maturation process of fruits and seeds of brazilwood in three different plantations in São Paulo State. Individual flowers were tagged in the day of their anthesis and the pods were collected directly from the branches until 65 days after anthesis (DAA). Results obtained suggested that physiological maturity of brazilwood seeds occurred $c a$. $60-65$ DAA, immediately before shedding, when seeds had $30-40 \%$ water content, as well as an efficient control of the water flux between seeds and fruits during their maturation.

Keywords: Caesalpinia echinata, harvesting, Paubrasilia echinata, physiological maturity, seed germination
\end{abstract}

RESUMO - (Regulação hídrica entre frutos e sementes de pau-brasil durante sua maturação). O pau-brasil, Paubrasilia echinata E.Gagnon, H.C.Lima \& G.P.Lewis, é uma das mais importantes espécies vegetais do Brasil. Muitos fatores podem interferir na manutenção da viabilidade e na conservação das sementes, principalmente sua qualidade fisiológica inicial. Entre outros fatores, esta qualidade depende do grau de maturação, sendo importante identificar a maturidade fisiológica com vistas a determinar o melhor momento para a colheita das sementes. O presente trabalho descreve as modificações que ocorrem durante o processo de maturação das sementes de pau-brasil em três diferentes locais no Estado de São Paulo. Flores foram etiquetadas no dia de sua antese e os frutos foram colhidos diretamente dos ramos até os 65 dias após a antese (DAA). Os resultados sugerem que a maturidade fisiológica das sementes de pau-brasil ocorreu por volta de 60-65 DAA, imediatamente antes da deiscência da vagem, quando as sementes tinham $30-40 \%$ de água e quando há eficiente controle do fluxo de água entre sementes e frutos durante a maturação.

Palavras-chave: Caesalpinia echinata, colheita, germinação de sementes, maturidade fisiológica, Paubrasilia echinata.

\section{Introdução}

A Mata Atlântica brasileira teve longo histórico de devastação iniciada na época do descobrimento do Brasil, com a exploração de diversas espécies vegetais e animais. Entre estas espécies, o pau-brasil (Caesalpinia echinata
Lam., recentemente sinonimizada como Paubrasilia echinata por E.Gagnon, H.C.Lima \& G.P.Lewis - Gagnon et al. 2016), então utilizado para o tingimento de tecidos, foi extensamente removido por toda a sua área de ocorrência natural. Em tempos mais recentes, a espécie é apreciada por fabricantes de arcos de violinos em todo o mundo,

1. Corteva Agriscience, Product Stewardship \& Sustainability, Alameda Itapecuru, 506, Alphaville, 06454-080 Barueri, SP, Brasil

2. Instituto de Botânica, Núcleo de Pesquisa em Fisiologia Vegetal, Avenida Miguel Stéfano, 3687, 04301-012 São Paulo, SP, Brasil

3. Instituto de Botânica, Núcleo de Pesquisa em Sementes, Avenida Miguel Stéfano, 3687, 04301-012 São Paulo, SP, Brasil

4. Autor para correspondência: cjbarbedo@yahoo.com.br 
pois sua madeira apresenta propriedades acústicas únicas (Angyalossy et al. 2005, Figueiredo-Ribeiro et al. 2008). Atualmente, sua população está restrita a poucas áreas naturais e reservas experimentais (Figueiredo-Ribeiro et al. 2008). Neste panorama da importância e da exploração do pau-brasil até os dias atuais, é evidente a necessidade do desenvolvimento de ações que criem subsídios tanto para permitir a reposição desta espécie no bioma quanto para manter bancos de germoplasma ex situ, especialmente com o armazenamento das sementes.

A composição de bancos de germoplasma por sementes é baseada na tecnologia para impedir a perda de sua viabilidade que, por sua vez, depende da obtenção de lotes de elevada qualidade (Barbedo \& Santos Junior 2018). Por meio de estudos de maturação é possível identificar o momento ideal de coleta das sementes durante o seu processo de desenvolvimento e, assim, obter lotes com elevada qualidade (Marcos Filho 2015). Em relação ao pau-brasil, o período de floração, de uma forma geral em áreas in situ e ex situ, ocorre entre setembro e novembro, mas pode em algumas áreas naturais ser estendido até janeiro (Cunha \& Lima 1992). Essas variações podem estar relacionadas a diferenças ambientais específicas em cada região como temperatura e fotoperíodo ou, ainda, à variabilidade genética de cada população (Summerfield et al. 1997). Contudo, são raros os estudos de maturação das sementes dessa espécie (Borges et al. 2005).

$\mathrm{O}$ reconhecimento da maturidade fisiológica das sementes, ou seja, o momento no qual as sementes atingem o máximo acúmulo de massa seca, bem como maiores germinabilidade e vigor, é fundamental para a obtenção de sementes de elevada qualidade (Barbedo \& Santos Junior 2018). A colheita prévia à maturidade das sementes pode gerar lotes com sementes malformadas e, consequentemente, com baixo vigor; e essas podem ter sua manutenção da viabilidade durante o armazenamento prejudicada (Mello et al. 2013, Santos \& Barbedo 2017) ou apresentar problemas durante a germinação, quer pelo incompleto desenvolvimento do eixo embrionário, quer pela falta de acúmulo de compostos de reserva necessários à germinação (Barbedo \& Santos Junior 2018).

A maturidade fisiológica pode variar em diferentes populações de uma mesma espécie, visto que fatores genéticos, bióticos e abióticos são determinantes para o desenvolvimento e maturação das sementes. Além disso, devido ao fato de que a antese das flores de alguns indivíduos pode não ocorrer uniformemente, é possível que sementes sejam dispersas com diferentes graus de maturação em um mesmo indivíduo (Borges et al. 2005, Marcos Filho 2015, Barbedo \& Santos Junior 2018). Portanto, estudos comparativos da maturação de sementes de pau-brasil em diferentes regiões são essenciais para fornecer subsídios à identificação do melhor momento de colheita de sementes de pau-brasil e, ainda, verificar influências de diferentes fatores ambientais na formação dessas sementes.
Outro aspecto importante, nos estudos de maturação de sementes, e pouco investigado, é a dinâmica de movimentação da água entre frutos e sementes durante a formação de ambos. Há relatos de que o teor de água das sementes de frutos carnosos, por exemplo, tende a ser mais elevado durante a maturação que o de sementes de frutos secos (Marcos Filho 2015), mas são raros os estudos que acompanham a evolução do teor de água dos frutos simultaneamente ao das sementes. É esperado um gradiente de potencial hídrico que mantenha o fluxo de água em direção à semente, como ocorre com a movimentação de água em toda a planta (Taiz \& Zeiger); contudo, entre frutos e sementes, pouco é conhecido, sendo necessário o monitoramento tanto do potencial quando do teor de água de frutos e sementes.

Este trabalho teve o objetivo de analisar as modificações físicas e fisiológicas em sementes de pau-brasil durante o processo de maturação em bosques plantados no Estado de São Paulo sob condições ambientais diferentes, buscando estabelecer parâmetros para a identificação da maturidade fisiológica e comparar as principais diferenças e semelhanças entre estas modificações, bem como identificar a regulação hídrica entre sementes e frutos durante a maturação.

\section{Material e métodos}

Obtenção do material de estudo - as sementes e frutos de pau-brasil utilizadas neste estudo foram coletadas em bosques homogêneos plantados e já estabelecidos no Jardim Botânico Municipal "Chico Mendes", no município de

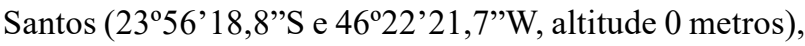
no Jardim Botânico de São Paulo, no município de São

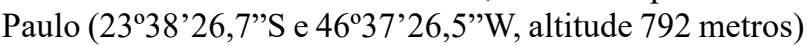
e no Jardim Zoobotânico de Franca, no município de Franca (202 $8^{\prime} 33,4^{\prime \prime}$ S e $47^{\circ} 24^{\prime} 18,5^{\prime \prime} \mathrm{W}$, altitude 923 metros), Estado de São Paulo, Brasil. Durante 20 dias no período de máximo florescimento da espécie, foram marcadas inflorescências que apresentavam a maior parte das flores em antese como início da contagem cronológica para as colheitas, em dias após a antese (DAA). A partir daí, frutos foram colhidos aos 43, 50 e 60 DAA (em Santos), aos 33, 41, 50 e 60 DAA (em São Paulo) e aos 28, 35, 44,53 e 60 DAA (em Franca), que foram consideradas as idades de frutos e de sementes para as análises realizadas posteriormente. Para o estudo em São Paulo também foram obtidas, após cerca de 65-70 DAA, sementes dispersas naturalmente sobre sombrite disposto sob o bosque, por um período inferior a 24 horas, denominadas sementes recém-dispersas (SRD).

Após as coletas, o material vegetal foi transportado imediatamente para o laboratório de Sementes do Instituto de Botânica, em São Paulo, onde os frutos foram abertos manualmente (exceto para as sementes SRD de São Paulo) para obtenção das sementes. 
Análise das características externas de frutos e sementes - Durante o estudo de maturação foram registradas as características visuais externas dos frutos e de sementes, tais como cor predominante, flexibilidade, opacidade, presença e característica de acúleos e presença de manchas. Além disso, com paquímetro digital foram tomadas as dimensões de frutos e sementes, da seguinte forma: 1) do fruto, o comprimento total, a largura medial e as espessuras medial e maior, esta caracterizada pela espessura no ponto com a maior semente (doravante denominada apenas maior espessura); 2) das sementes, o comprimento, a largura e a espessura.

Determinações físicas e fisiológicas das sementes - O teor de água (expresso em porcentagem, em base úmida) dos frutos e das sementes e o conteúdo de massa seca das sementes $\left(\mathrm{mg}\right.$ semente $\left.^{-1}\right)$ foram obtidos, para cada estádio de maturação, por secagem em estufa à $103{ }^{\circ} \mathrm{C}$ por 17 horas (Brasil 2009). Adicionalmente, para os materiais obtidos em Franca, também foram analisados o teor de água e o conteúdo de massa seca de cotilédones, de eixos embrionários e de tegumentos das sementes, separadamente.

$\mathrm{O}$ teste de germinação foi realizado em germinadores Marconi tipo MA400 com circulação interna de água, a $25 \pm 1{ }^{\circ} \mathrm{C}$, com fotoperíodo de 12 horas e $100 \%$ UR, conforme informações de Mello \& Barbedo (2007). As sementes foram colocadas em rolo de papel para germinação (Germitest), umedecidos previamente com água até sua saturação e escorridos para eliminação do excesso (Brasil 2009). As contagens para este teste foram iniciadas a partir do segundo dia, em dias alternados, quando foram registradas as sementes com protrusão da raiz primária de, no mínimo, $5 \mathrm{~mm}$ (para o cálculo da germinação), as plântulas com desenvolvimento normal (para o cálculo de plântulas normais), ou seja, presença de sistema radicular e de parte aérea, ambos sem defeitos aparentes, segundo Barbedo et al. (2002) e as plântulas com desenvolvimento normal e vigoroso (plântulas com mais de $5 \mathrm{~cm}$ do colo à extremidade do primeiro par de folhas primárias, no $20^{\circ}$ dia contado a partir do início do teste), para o cálculo de plântulas vigorosas. Foi calculado, ainda, o Índice de Velocidade de Germinação (IVG), com adaptação da fórmula de Índice de Velocidade de Emergência (Maguire 1962): $I V G=\left(G_{1} / N_{1}\right)+\left(G_{2} / N_{2}\right)+\ldots+\left(G_{n} / N_{n}\right)$, onde $G_{1}, G_{2}, G_{n}$ representam o número de novas sementes germinadas no dia $\mathrm{N}_{1}, \mathrm{~N}_{2}, \mathrm{~N}_{\mathrm{n}}$ de avaliação.

Para análise comparativa entre o teor de água dos frutos e das sementes e a real energia e disponibilidade da água nestes tecidos, o potencial hídrico ( $\Psi$, em MPa) dos frutos e das sementes nos diferentes estádios de maturação também foi analisado, por meio de medidor WP4 Dewpoint Potentiameter (Decagon Devices, Inc., Pullman), o qual se baseia na temperatura do ponto de orvalho do ar quando em equilíbrio higroscópico com a amostra avaliada (Decagon 2001). Adicionalmente, para os materiais obtidos em
Franca, também foi analisado o $\Psi$ dos cotilédones, eixos embrionários e tegumentos das sementes, separadamente.

Delineamento experimental e análise estatística - $\mathrm{O}$ delineamento experimental foi inteiramente casualizado, com quatro repetições em todos os testes. Os resultados foram submetidos à análise de variância pelo teste $\mathrm{F}$ ao nível de 5\%. Em seguida, para os resultados obtidos em Franca e São Paulo foram ajustadas regressões polinomiais (Steel \& Torrie 1980), enquanto que para os resultados provenientes de Santos, devido ao menor número de estádios de maturação obtidos, as médias foram comparadas pelo teste de Tukey, ao nível de 5\% (Gomes 1982). Quando necessário para correção da normalidade e da heterogeneidade, os dados em porcentagem foram transformados para arc sen $\sqrt{ } \%$ (Santana \& Ranal 2004).

\section{Resultados e Discussão}

O início do florescimento de pau-brasil ocorreu primeiro em Franca, na segunda quinzena de agosto, seguido por São Paulo, na primeira quinzena de setembro e em Santos, na primeira quinzena de outubro. A variação no início do florescimento de pau-brasil pode ocorrer até em uma mesma região, de um ano para outro, conforme observaram Borges $e t$ al. (2005) em uma população de pau-brasil plantada em área de cerrado. Segundo os autores, a diferença observada de 15 dias no início do florescimento entre dois anos consecutivos pode estar relacionada à precipitação pluvial, pois no período com menor quantidade de chuvas o florescimento ocorreu 15 dias mais cedo.

O processo de desenvolvimento e maturação das sementes pode ser dividido em três fases distintas: I histodiferenciação ou embriogênese; II - desenvolvimento e acúmulo de massa seca; III - maturação propriamente dita e secagem (Kermode 1990, Marcos Filho 2015, Silva et al. 2018). A fase I, identificada no primeiro mês após a formação do zigoto para pau-brasil, foi estudada por Teixeira et al. (2004). No presente estudo as modificações morfológicas e fisiológicas ocorreram nas fases II e III. Nestas, predominou a coloração verde dos frutos de todas as populações avaliadas, com tonalidade mais clara e com acúleos flexíveis entre os 28 e 44 DAA e mais escura, algumas vezes com pequenas manchas de coloração castanho claro, a partir dos 50 DAA. No entanto, aos 60 DAA os frutos já apresentavam grandes áreas com manchas castanhas ou estavam totalmente pigmentados por esta cor, inclusive seus acúleos que já estavam rígidos (tabela 1 ).

Em todas as populações avaliadas o comprimento dos frutos foi constante desde os primeiros estádios avaliados ( 28 DAA em Franca) até o momento anterior à dispersão, com valores entre 63 a $69 \mathrm{~mm}$ (figura 1 e tabela 2). Apesar de no final da maturação a largura dos frutos ter sido próxima a $22,50 \mathrm{~mm}$, esta característica apresentou variações entre as populações, pois, enquanto os frutos provenientes de Santos 
Tabela 1. Características externas de frutos e de sementes de pau-brasil, Paubrasilia echinata E.Gagnon, H.C.Lima \& G.P.Lewis, obtidas nos municípios de Franca, São Paulo e Santos, Estado de São Paulo, Brasil, durante o desenvolvimento e maturação.

Table 1. External characteristics of pods and seeds of Paubrasilia echinata E.Gagnon, H.C.Lima \& G.P.Lewis during development and maturation, obtained in Franca, São Paulo and Santos, São Paulo State, Brazil.

\begin{tabular}{|c|c|c|c|}
\hline $\mathrm{DAA}^{1}$ & Fase $^{3}$ & Características dos Frutos & Características das Sementes \\
\hline $28-44$ & II & Verde-claros, flexíveis, acúleos verdes e flexíveis & Verde-claras, brilhantes e bem flexíveis \\
\hline $50-60$ & II & $\begin{array}{l}\text { Verde-escuros, pouco flexíveis, algumas manchas } \\
\text { castanhas, acúleos verde-escuros ou castanhos e } \\
\text { pouco flexíveis }\end{array}$ & $\begin{array}{l}\text { Verde-escuras, pouco flexíveis e as vezes } \\
\text { com manchas púrpuras ou castanhas }\end{array}$ \\
\hline $60-\mathrm{dn}^{2}$ & III & Castanhos, rígidos e com acúleos castanhos e rígidos & Castanhas, rígidas e com manchas púrpuras \\
\hline
\end{tabular}

${ }^{1}$ DAA: dias após a antese; ${ }^{2} \mathrm{dn}$ : dispersão natural; ${ }^{3}$ Fase I: histodiferenciação (Teixeira et al. 2004); Fase II: desenvolvimento/acúmulo de matéria seca; Fase III: final da maturação/dessecação.

${ }^{1}$ DAA: days after anthesis; ${ }^{2} \mathrm{dn}$ : natural dispersion; ${ }^{3}$ Phase I: histodifferentiation (Teixeira et al. 2004); Phase II: development/dry mass accumulation; Phase III: final maturation/drying.
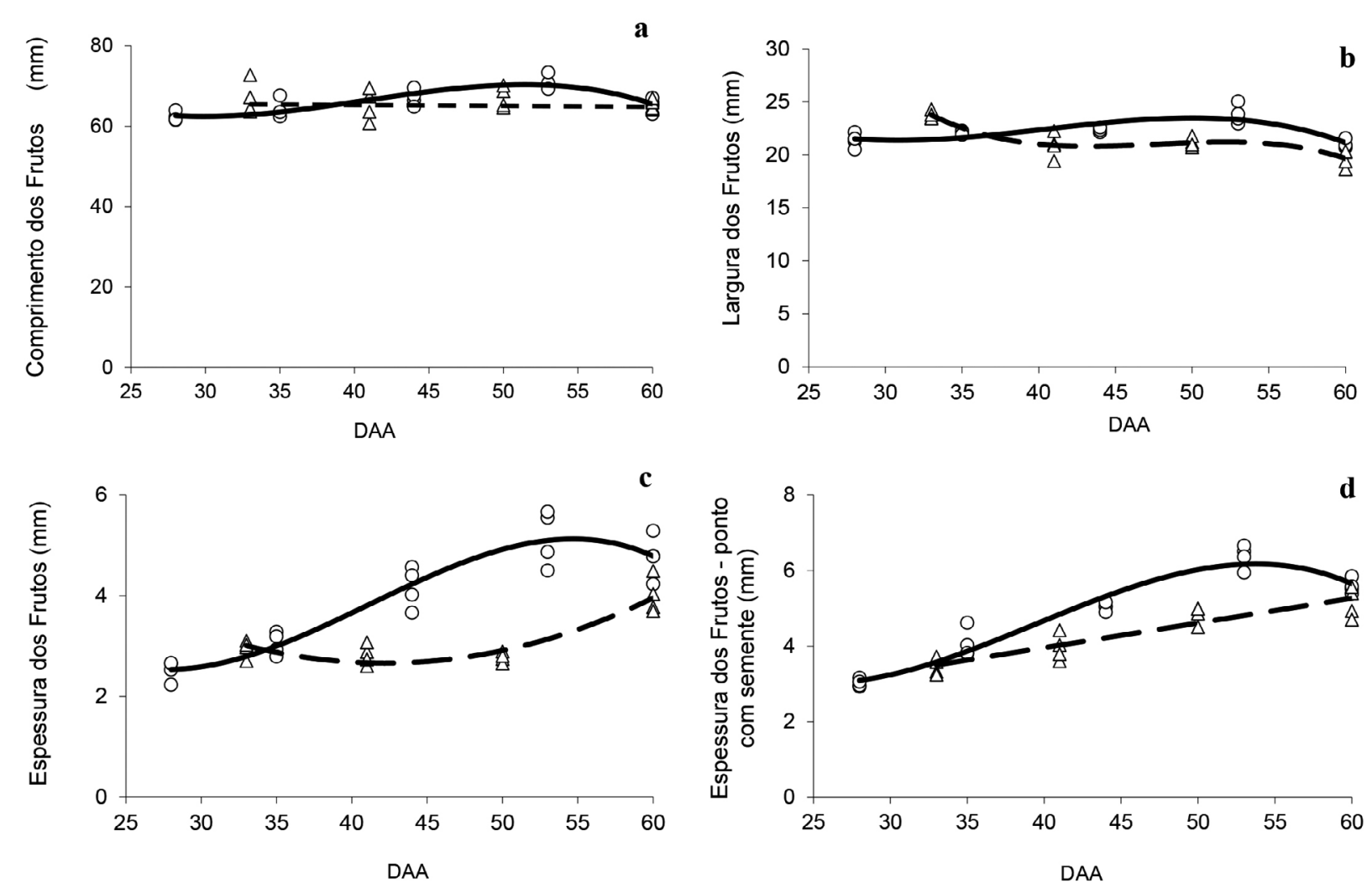

Figura 1. Dimensões (a: comprimento; b: largura; c: espessura; d: espessura no ponto com semente) dos frutos de Paubrasilia echinata E.Gagnon, H.C.Lima \& G.P.Lewis obtidos nos municípios de Franca ( $\bigcirc$, linha cheia) e São Paulo $(\triangle$, linha tracejada), Estado de São Paulo, Brasil, durante o desenvolvimento e maturação. Regressões $(\mathrm{p}<0,05)$ : $\mathrm{Y}_{(\mathrm{a})} \mathrm{O}=-0,0016 \mathrm{X}^{3}+0,195 \mathrm{X}^{2}-7,394 \mathrm{X}+151,642, \mathrm{r}^{2}=0,73, \mathrm{CV}=$ $2,75 \% ; Y_{(a)} \triangle=66,20 ; Y_{(b)} O=-0,0006 X^{3}+0,073 X^{2}-2,792 X+55,560, r^{2}=0,63, C V=2,49 \% ; Y_{(b)} \triangle=-0,0012 X^{3}+0,172 X^{2}-8,116 X+147,74$, $\mathrm{r}^{2}=0,83, \stackrel{\mathrm{CV}}{\mathrm{C}}=3,58 \% ; \mathrm{Y}_{(\mathrm{c})} \mathrm{O}=-0,0003 \mathrm{X}^{3}+0,032 \mathrm{X}^{2}-1,200 \mathrm{X}+16,343, \mathrm{r}^{2}=0,90, \mathrm{CV}=9,89 \% ; \mathrm{Y}_{\text {(c) }} \triangle=0,004 \mathrm{X}^{2}-0,345 \mathrm{X}+9,931, \mathrm{r}^{2}=0,82$, $\mathrm{CV}=7,33 \% ; \mathrm{Y}_{(\mathrm{d})} \mathrm{O}=-0,0003 \mathrm{X}^{3}+0,033 \mathrm{X}^{2}-1,122 \mathrm{X}+14,973, \mathrm{r}^{2}=0,94, \mathrm{CV}=5,08 \% ; \mathrm{Y}_{(\mathrm{d})} \triangle=0,065 \mathrm{X}+1,343, \mathrm{r}^{2}=0,83, \mathrm{CV}=7,17 \%$.

Figure 1. Dimensions (a: length; b: width; c: thickness; d: thickness at the point with seed) of fruits of Paubrasilia echinata E.Gagnon, H.C.Lima \& G.P.Lewis obtained in Franca ( $O$, full line) and São Paulo ( $\triangle$, dashed line), São Paulo State, Brazil, during the development and maturation. Regressions $(\mathrm{p}<0.05)$ : $\mathrm{Y}_{(\mathrm{a})} \mathrm{O}=-0.0016 \mathrm{X}^{3}+0.195 \mathrm{X}^{2}-7.394 \mathrm{X}+151.642, \mathrm{r}^{2}=0.73, \mathrm{CV}=2.75 \% ; \mathrm{Y}_{(\mathrm{a})} \triangle=66.20 ; \mathrm{Y}_{(\mathrm{b})} \mathrm{O}$ $=-0.0006 \mathrm{X}^{3}+0.073 \mathrm{X}^{2}-2.792 \mathrm{X}+55.560, \mathrm{r}^{2} \stackrel{\text { (a) }}{=} 0.63, \mathrm{CV}=2.49 \% ; \mathrm{Y}_{(\mathrm{b})} \triangle=-0.0012 \mathrm{X}^{3}+0.172 \mathrm{X}^{2}-8.116 \mathrm{X}+147.74, \mathrm{r}^{2}=0.83, \mathrm{CV}=3.58 \%$; $\mathrm{Y}_{(\mathrm{c})} \mathrm{O}=-0.0003 \mathrm{X}^{3}+0.032 \mathrm{X}^{2}-1.200 \mathrm{X}+16.343, \mathrm{r}^{2}=0.90, \mathrm{CV}=9.89 \% ; \mathrm{Y}_{(\mathrm{c})} \triangle=0.004 \mathrm{X}^{2}-0.345 \mathrm{X}+9.931, \mathrm{r}^{2}=0.82, \mathrm{CV}=7.33 \% ; \mathrm{Y}$ (d) $\mathrm{O}=$ $-0.0003 \mathrm{X}^{3}+0.033 \mathrm{X}^{2}-1.122 \mathrm{X}+14.973, \mathrm{r}^{2}=0.94, \mathrm{CV}=5.08 \% ; \mathrm{Y}_{(\mathrm{d})} \triangle=0.065 \mathrm{X}+1.343, \mathrm{r}^{2}=0.83, \mathrm{CV}=7.17 \%$ 
Tabela 2. Medidas físicas e fisiológicas de frutos e sementes de pau-brasil, Paubrasilia echinata E.Gagnon, H.C.Lima \& G.P.Lewis, obtidas no município de Santos, Estado de São Paulo, Brasil, durante o desenvolvimento e maturação.

Table 2. Fruits and seeds physical and physiological measures of Paubrasilia echinata E.Gagnon, H.C.Lima \& G.P.Lewis during development and maturation, obtained in Santos, São Paulo State, Brazil.

\begin{tabular}{|c|c|c|c|c|}
\hline \multirow{2}{*}{ Variáveis } & \multicolumn{3}{|c|}{ Dias após antese } & \multirow{2}{*}{$\begin{array}{l}\text { C.V. } \\
(\%)\end{array}$} \\
\hline & 43 & 50 & 60 & \\
\hline Comprimento dos frutos (mm) & $63,97 b^{*}$ & $65,10 \mathrm{~b}$ & $68,83 a$ & 2,74 \\
\hline Largura dos frutos $(\mathrm{mm})$ & $21,27 \mathrm{c}$ & $22,31 b$ & $23,52 \mathrm{a}$ & 2,25 \\
\hline Espessura medial dos frutos (mm) & $3,38 b$ & $4,32 \mathrm{a}$ & $4,26 a b$ & 10,40 \\
\hline Maior espessura dos frutos $(\mathrm{mm})$ & $5,35 \mathrm{a}$ & $5,80 \mathrm{a}$ & $5,60 \mathrm{a}$ & 5,00 \\
\hline Comprimento das sementes (mm) & $16,39 \mathrm{a}$ & $17,07 \mathrm{a}$ & $17,17 \mathrm{a}$ & 3,16 \\
\hline Largura das sementes $(\mathrm{mm})$ & $14,06 \mathrm{a}$ & $14,26 \mathrm{a}$ & $13,47 \mathrm{a}$ & 3,07 \\
\hline Espessura das sementes (mm) & $3,23 b$ & $3,59 \mathrm{a}$ & $3,32 b$ & 4,03 \\
\hline Teor de água das sementes (\%) & $63,5 \mathrm{a}$ & $62,3 \mathrm{a}$ & $36,5 b$ & 4,94 \\
\hline Teor de água dos frutos (\%) & $48,7 \mathrm{a}$ & $48,5 \mathrm{a}$ & $22,1 b$ & 2,34 \\
\hline Potencial hídrico das sementes (MPa) & $-2,1 b$ & $-2,0 b$ & $-7,5 \mathrm{a}$ & 43,92 \\
\hline Potencial hídrico dos frutos (MPa) & $-2,4 b$ & $-2,3 b$ & $-13,7 \mathrm{a}$ & 12,18 \\
\hline Massa seca das sementes (mg. semente ${ }^{-1}$ ) & $161,75 b$ & $194,00 \mathrm{~b}$ & $308,67 \mathrm{a}$ & 11,83 \\
\hline Germinação (\%) & $30 \mathrm{c}$ & $60 \mathrm{~b}$ & $93 \mathrm{a}$ & 22,43 \\
\hline Plântulas com desenvolvimento normal (\%) & $0 \mathrm{~b}$ & $20 \mathrm{~b}$ & $80 \mathrm{a}$ & 31,62 \\
\hline Plântulas vigorosas (\%) & $0 \mathrm{~b}$ & $0 \mathrm{~b}$ & $67 \mathrm{a}$ & 12,52 \\
\hline IVG & $0,40 \mathrm{c}$ & $0,90 \mathrm{~b}$ & $2,88 \mathrm{a}$ & 12,89 \\
\hline
\end{tabular}

*Médias dentro de cada variável, seguidas pela mesma letra não diferem entre si pelo teste de Tukey, ao nível de 5\% de probabilidade.

* Means within each variable and followed by the same letter did not differ by Tukey's test at $5 \%$.

atingiram este valor por aumento progressivo dos 43 aos 60 DAA (tabela 2), em São Paulo ocorreu o comportamento inverso dos 33 aos 60 DAA (figura 2), e em Franca a largura praticamente não foi alterada. Contudo, apesar das diferenças significativas, as alterações em largura foram pouco pronunciadas desde a primeira época de coleta (28 DAA). Estas dimensões dos frutos são concomitantes às reportadas por Lewis (1998) para a espécie, ou seja, 6-8 $\mathrm{cm}$ de comprimento e 2-3 cm de largura.

De uma forma geral, o comportamento entre espessura medial e maior espessura foi praticamente o mesmo para cada uma das populações, variando cerca de 2,00 $\mathrm{mm}$ (figura 1 e tabela 2). Considerando esta similaridade, a espessura final dos frutos foi semelhante entre as populações, ou seja, aproximadamente $5,60 \mathrm{~mm}$. No entanto, enquanto em Santos esta dimensão não apresentou mudanças no comportamento, para as outras duas populações, o máximo de espessura foi atingido após constante aumento do início ao final da maturação. $\mathrm{O}$ fato das dimensões dos frutos atingirem valores máximos logo no início do processo de maturação, observado também em outras espécies como Poincianella pluviosa (Silva et al. 2015), poderia estar relacionado a um maior direcionamento de reservas da planta para a formação rápida do fruto.

A mudança na coloração das sementes acompanhou, em todas as populações, o mesmo padrão encontrado nos frutos, permanecendo verde claras durante quase todo o período de desenvolvimento, iniciando o escurecimento e o surgimento 

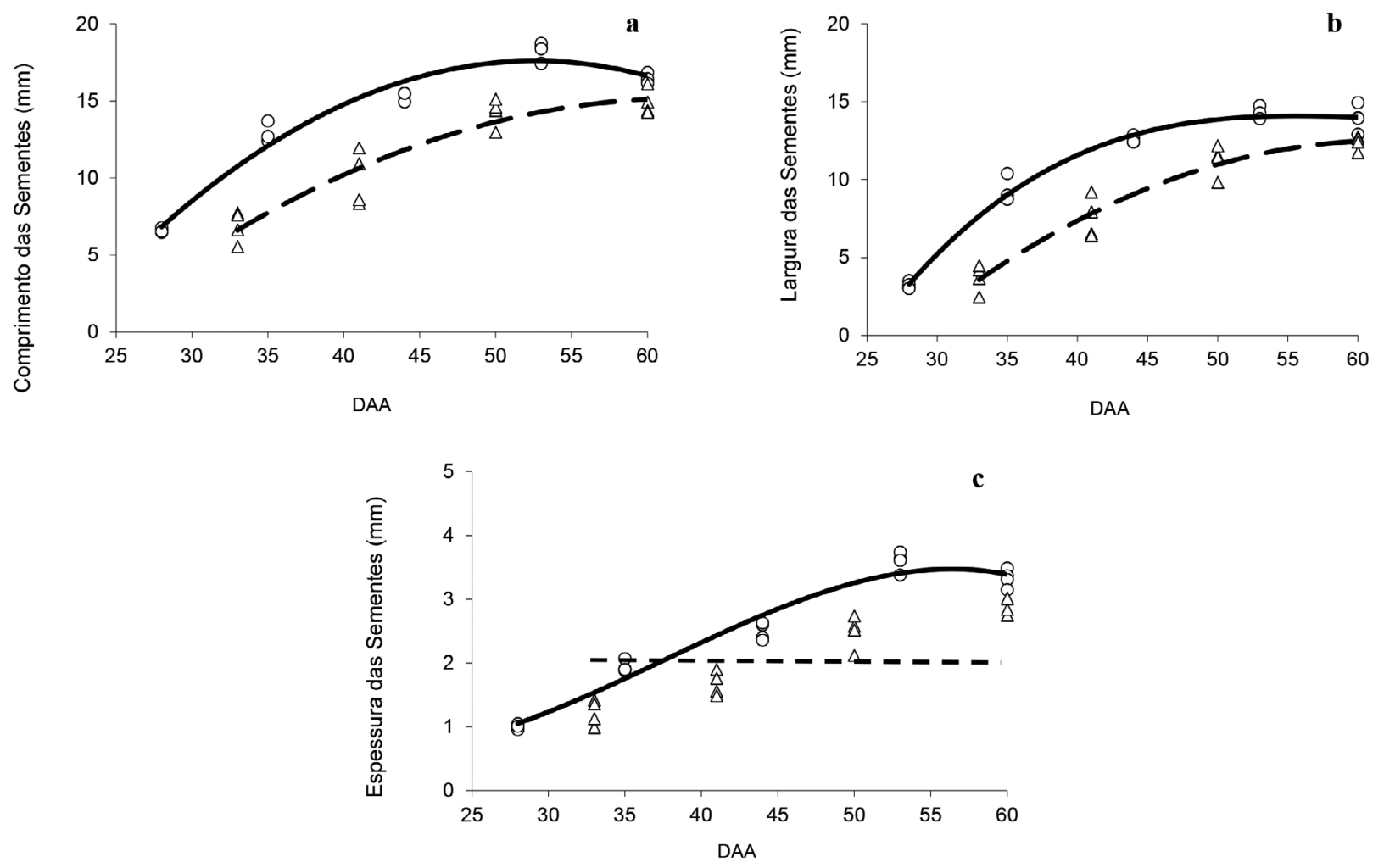

Figura 2. Dimensões (a: comprimento; b: largura; c: espessura) das sementes de Paubrasilia echinata E.Gagnon, H.C.Lima \& G.P.Lewis obtidas nos municípios de Franca $(O$, linha cheia) e São Paulo ( $\triangle$, linha tracejado), Estado de São Paulo, Brasil, durante o desenvolvimento e maturação. Regressões $(\mathrm{p}<0,05)$ : $\mathrm{Y}_{\text {(a) }} \mathrm{O}=-0,018 \mathrm{X}^{2}+1,873 \mathrm{X}-31,659, \mathrm{r}^{2}=0,97, \mathrm{CV}=3,00 \% ; \mathrm{Y}_{\text {(a) }} \triangle=-0,010 \mathrm{X}^{2}+1,236 \mathrm{X}-23,371, \mathrm{r}^{2}=0,89$, $\mathrm{CV}=10,38 \% ; \mathrm{Y}_{\text {(b) }} \mathrm{O}=0,0003 \mathrm{X}^{3}-0,059 \mathrm{X}^{2}+3,564 \mathrm{X}-57,470, \mathrm{r}^{2}=0,98, \mathrm{CV}=5,20 \% ; \mathrm{Y}_{\text {(b) }} \triangle=-0,010 \mathrm{X}^{2}+1,312 \mathrm{X}-28,202, \mathrm{r}^{2}=0,94, \mathrm{CV}=$ $11,10 \% ; \mathrm{Y}_{\text {(c) }} \mathrm{O}=-0,0001 \mathrm{X}^{3}+0,012 \mathrm{X}^{2}-0,343 \mathrm{X}+3,498, \mathrm{r}^{2}=0,96, \mathrm{CV}=4,84 \% ; \mathrm{Y}_{\text {(c) }} \triangle=2,07$.

Figure 2. Dimensions (a: length; b: width; c: thickness) of seeds of Paubrasilia echinata E.Gagnon, H.C.Lima \& G.P.Lewis obtained in Franca $(O$, full line) and São Paulo $(\triangle$, dashed line), São Paulo State, Brazil, during the development and maturation. Regressions $(\mathrm{p}<0.05): \mathrm{Y}_{(\mathrm{a})} \mathrm{O}=-0.018 \mathrm{X}^{2}+1.873 \mathrm{X}-31.659, \mathrm{r}^{2}=0.97, \mathrm{CV}=3.00 \% ; \mathrm{Y}_{(\mathrm{a})} \triangle=-0.010 \mathrm{X}^{2}+1.236 \mathrm{X}-23.371, \mathrm{r}^{2}=0.89, \mathrm{CV}=10.38 \% ; \mathrm{Y}$ (b) $\mathrm{O}$ $=0.0003 \mathrm{X}^{3}-0.059 \mathrm{X}^{2}+3.564 \mathrm{X}-57.470, \mathrm{r}^{2}=0.98, \mathrm{CV}=5.20 \% ; \mathrm{Y}_{(\mathrm{b})} \stackrel{(\mathrm{a})}{=}-0.010 \mathrm{X}^{2}+1.312 \mathrm{X}-28.202, \mathrm{r}^{2}=0.94, \mathrm{CV}=11.10 \% ; \mathrm{Y}$ (c) $\stackrel{\mathrm{O}}{\mathrm{O}}=$ $-0.0001 \mathrm{X}^{3}+0.012 \mathrm{X}^{2}-0.343 \mathrm{X}+3.498, \mathrm{r}^{2}=0.96, \mathrm{CV}=4.84 \% ; \mathrm{Y}_{(\mathrm{c})} \triangle=2.07$.

de algumas manchas violáceas somente a partir dos 50 DAA, seguido da passagem para a coloração parda apenas aos 60 DAA (tabela 1). As sementes das populações de São Paulo e de Franca apresentaram evolução do comprimento e da largura semelhantes, com aumento progressivo nestas dimensões durante a maior parte do processo seguido por uma estabilização do crescimento na fase final da maturação, atingido aproximadamente $15,50 \mathrm{~mm}$ em comprimento e 13,00 mm em largura aos 60 DAA (figura 2). Contudo, em Santos, apesar das sementes apresentarem valores um pouco superiores, ou seja, $17,17 \mathrm{~mm}$ em comprimento e 13,47 $\mathrm{mm}$ em largura, não houve diferenças significativas entre os diferentes estádios analisados (tabela 2). A espessura das sementes no final do processo de maturação não variou consideravelmente entre as populações e atingiu, em média, $3,00 \mathrm{~mm}$. Contudo, em Santos e São Paulo essa dimensão final foi observada logo nas primeiras idades estudadas, enquanto que em Franca houve aumento das primeiras às últimas épocas de coleta, quando então se atingiram os mesmos níveis das outras duas populações (figura $2 \mathrm{e}$ tabela 2).

O teor de água das sementes, em todas as populações avaliadas, reduziu lentamente do início da maturação até aproximadamente 45-50 DAA, correspondendo à fase de intenso acúmulo de reservas (fase II - Kermode 1990, Marcos Filho 2015, Silva et al. 2018). A partir daí, apresentou queda mais rápida e contínua até o final do processo de maturação (figura 3 e tabela 2), o que já seria esperado uma vez que tais sementes são consideradas ortodoxas (Barbedo et al. 2002, Borges et al. 2005). Os teores de água atingidos pouco antes da dispersão natural das sementes, ao final da maturação, foram 46,4\%, 36,5\% e 34,7\%, respectivamente para Franca, Santos e São Paulo. Esses valores reforçam a afirmação de Borges et al. (2005) de que as sementes de pau-brasil são dispersas aos 65-70 DAA, quando estão com teor de água próximo a $35-40 \%$, correspondendo ao final da maturação 

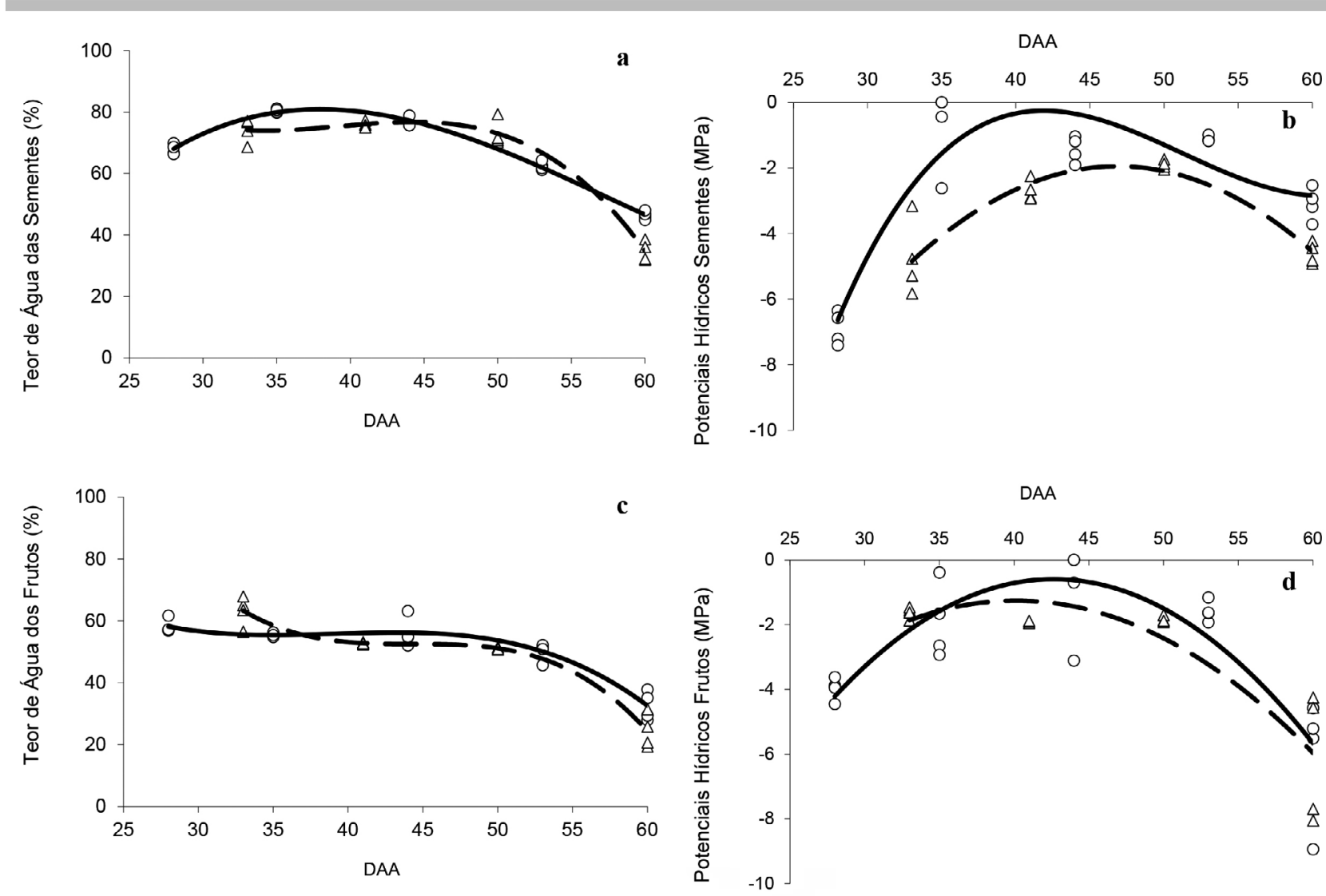

Figura 3. Teor de água de sementes (a) e frutos (c) e potenciais hídricos de sementes (b) e frutos (d) de Paubrasilia echinata E.Gagnon, H.C.Lima \& G.P.Lewis obtidos nos municípios de Franca ( $\bigcirc$, linha cheia) e São Paulo ( $\triangle$, linha tracejada), Estado de São Paulo, Brasil, durante o desenvolvimento e maturação. Regressões $(\mathrm{p}<0,05)$ : $\mathrm{Y}_{\text {(a) }} \mathrm{O}=0,0019 \mathrm{X}^{3}-0,324 \mathrm{X}^{2}+16,556 \mathrm{X}-182,114, \mathrm{r}^{2}=0,99, \mathrm{CV}=2,05 \%$; $\mathrm{Y}_{(\mathrm{a})} \triangle=-0,0055 \mathrm{X}^{3}+0,648 \mathrm{X}^{2}-25,004 \mathrm{X}+391,587, \mathrm{r}^{2}=0,97, \mathrm{CV}=5,19 \% ; \mathrm{Y}_{\text {(b) }} \mathrm{O}=-0,0029 \mathrm{X}^{3}+0,337 \mathrm{X}^{2}-13,049 \mathrm{X}+222,099, \mathrm{r}^{2}=0,91, \mathrm{CV}=$ $6,85 \% ; Y_{(b)} \triangle=-0,0073 X^{3}+0,977 X^{2}-43,371 X+693,952, r^{2}=0,95, C V=7,62 \% ; Y_{(c)} \mathrm{O}=-0,0008 X^{3}+0,121 X^{2}-6,007 X+97,075, r^{2}=0,84$, $\mathrm{CV}=25,16 \% ; \mathrm{Y}_{\text {(c) }} \triangle=0,015 \mathrm{X}^{2}-1,410 \mathrm{X}+34,987, \mathrm{r}^{2}=0,82, \mathrm{CV}=17,85 \% ; \mathrm{Y}_{\text {(d) }} \mathrm{O} \stackrel{\text { (c) }}{=} 0,017 \mathrm{X}^{2}-1,439 \mathrm{X}+31,287, \mathrm{r}^{2}=0,71, \mathrm{CV}=42,43 \%$; $\mathrm{Y}_{(\mathrm{d})} \triangle=0,012 \mathrm{X}^{2}-0,957 \mathrm{X}+20,463, \mathrm{r}^{2}=0,77, \mathrm{CV}=35,07 \%$.

Figure 3. Water content of seeds (a) and fruits (c) and water potential of seeds (b) and fruits (d) of Paubrasilia echinata E.Gagnon, H.C.Lima \& G.P.Lewis obtained in Franca $(O$, full line) and São Paulo $(\triangle$, dashed line), São Paulo State, Brazil, during the development and maturation. Regressions $(\mathrm{p}<0.05)$ : $\mathrm{Y}_{\text {(a) }} \mathrm{O}=0.0019 \mathrm{X}^{3}-0.324 \mathrm{X}^{2}+16.556 \mathrm{X}-182.114, \mathrm{r}^{2}=0.99, \mathrm{CV}=2.05 \% ; \mathrm{Y}$ (a) $\triangle=$ $-0.0055 \mathrm{X}^{3}+0.648 \mathrm{X}^{2}-25.004 \mathrm{X}+391.587, \mathrm{r}^{2}=0.97, \mathrm{CV}=5.19 \% ; \mathrm{Y}_{(\mathrm{b})} \mathrm{O}=-0.0029 \mathrm{X}^{3}+0.337 \mathrm{X}^{2}-13.049 \mathrm{X}+222.099, \mathrm{r}^{2}=0.91, \mathrm{CV}=6.85 \%$; $\mathrm{Y}_{(\mathrm{b})} \triangle=-0.0073 \mathrm{X}^{3}+0.977 \mathrm{X}^{2}-43.371 \mathrm{X}+693.952, \mathrm{r}^{2}=0.95, \mathrm{CV}=7.62 \% ; \mathrm{Y}_{(\mathrm{c})} \mathrm{O}=-0.0008 \mathrm{X}^{3}+0.121 \mathrm{X}^{2}-6.007 \mathrm{X}+97.075, \mathrm{r}^{2}=0.84, \mathrm{CV}=$ $25.16 \% ; \mathrm{Y}_{\text {(c) }} \triangle=0.015 \mathrm{X}^{2}-1.410 \mathrm{X}+34.987, \mathrm{r}^{2}=0.82, \mathrm{CV}=17.85 \% ; \mathrm{Y}_{\text {(d) }} \mathrm{O}=0.017 \mathrm{X}^{2}-1.439 \mathrm{X}+31.287, \mathrm{r}^{2}=0.71, \mathrm{CV}=42.43 \% ; \mathrm{Y}$ (d) $\triangle=$ $0.012 \mathrm{X}^{2}-0.957 \mathrm{X}+20.463, \mathrm{r}^{2}=0.77, \mathrm{CV}=35.07 \%$.

e secagem (fase III - Kermode 1990, Marcos Filho 2015, Silva et al. 2018). Além disso, o teor de água ao final da maturação classificaria as sementes de São Paulo como as mais maduras e as de Franca como as mais imaturas (Barbedo et al. 2013, Barbedo 2018). Segundo estes autores, o teor de água das sementes no momento em que são desligadas da planta-mãe pode definir o grau de ortodoxia ou recalcitrância das sementes. Em São Paulo, único local onde foi possível obter sementes recém-dispersas, estas estavam com teor de água bem menor (16,7\%), provavelmente pela exposição ao ar, ainda que por curto período (Silva et al. 2018).

Para as sementes de Franca, o teor de água, o potencial hídrico e o conteúdo de massa seca dos tegumentos, cotilédones e eixos embrionários, entre os 35 e 60 DAA, também foram analisados (figura 4). O teor de água, nestes três tecidos, reduziu constantemente do primeiro $(73,7 \%, 88,3 \%$ e $80,4 \%$, respectivamente para tegumentos, cotilédones e eixos embrionários) ao último estádio $(38,5 \%$, $34,6 \%$ e 44,4\%, respectivamente).

O teor de água dos frutos apresentou o mesmo comportamento de perda de água observado nas sementes, mas com valores inferiores, ou seja, partindo de 50,0\% de água e terminado com $25,0 \%$ de água em média para os três locais (figura 3 e tabela 2). As modificações nos teores de água de sementes e de frutos têm sido utilizadas como parâmetros adequados para caracterizar o estádio de 

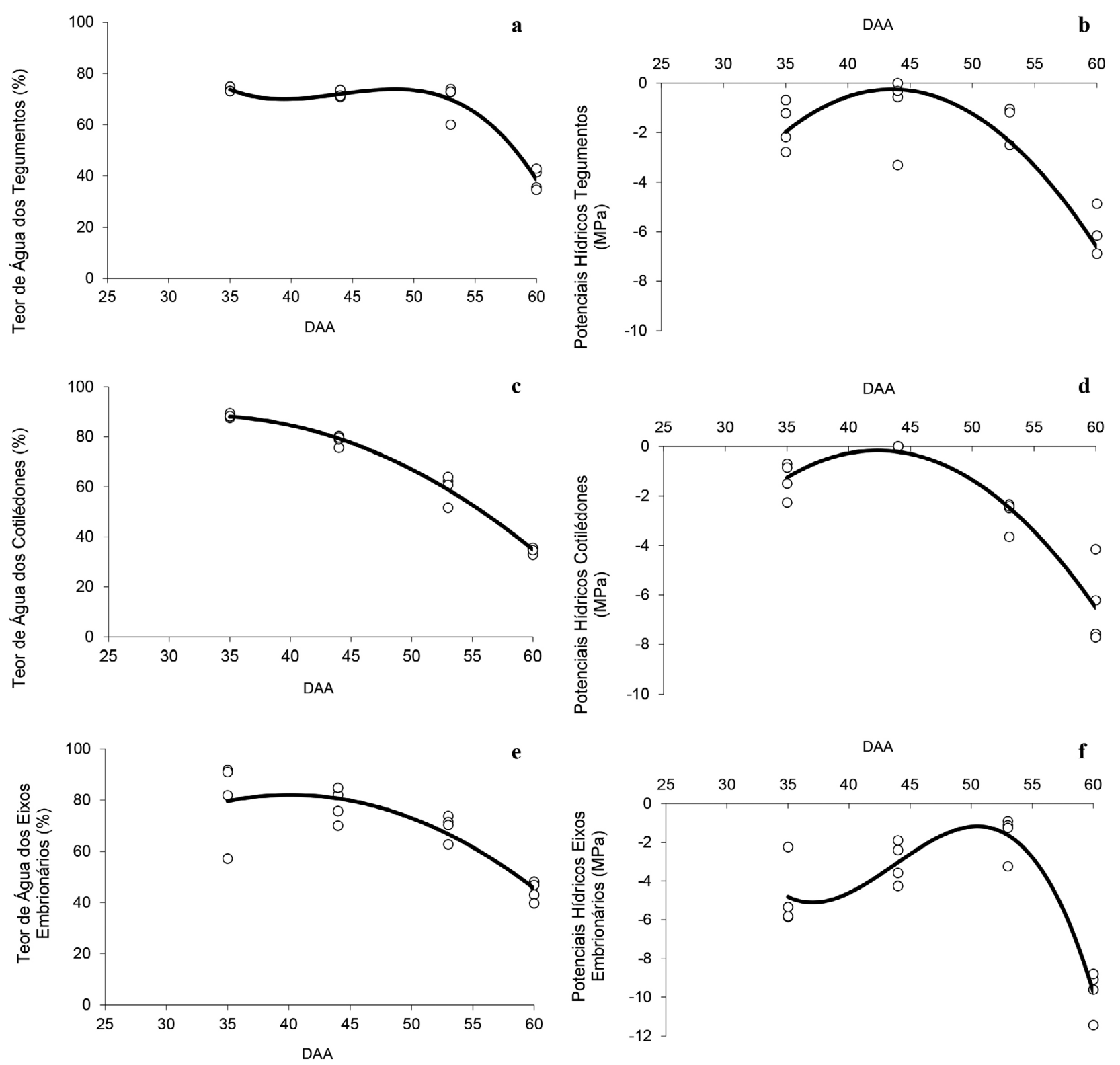

Figura 4. Teor de água de tegumentos (a), cotilédones (c) e eixos embrionários (e) e potenciais hídricos de tegumentos (b), cotilédones (d) e eixos embrionários (f) de sementes de Paubrasilia echinata E.Gagnon, H.C.Lima \& G.P.Lewis obtidas no município de Franca (O), Estado de São Paulo, Brasil, durante o desenvolvimento e maturação. Regressões $(\mathrm{p}<0,05)$ : $\mathrm{Y}_{(\mathrm{a})}=-0,0105 \mathrm{X}^{3}+1,384 \mathrm{X}^{2}-60,166 \mathrm{X}+934,205$, $\mathrm{r}^{2}=0,95, \mathrm{CV}=6,21 \% ; \mathrm{Y}_{(\mathrm{b})}=-0,072 \mathrm{X}^{2}+4,702 \mathrm{X}+11,574, \mathrm{r}^{2}=0,98, \mathrm{CV}=4,64 \% ; \mathrm{Y}_{(\mathrm{c})}=-0,092 \mathrm{X}^{2}+7,392 \mathrm{X}-66,264, \mathrm{r}^{2}=0,74, \mathrm{CV}=13,56 \%$; $\mathrm{Y}_{(\mathrm{d})}=0,023 \mathrm{X}^{2}-2,048 \mathrm{X}+44,850, \mathrm{r}^{2}=0,73, \mathrm{CV}=52,19 \% ; \mathrm{Y}_{(\mathrm{e})}=0,020 \mathrm{X}^{2}-1,727 \mathrm{X}+36,737, \mathrm{r}^{2}=0,89, \mathrm{CV}=36,23 \% ; \mathrm{Y}_{(\mathrm{f})}=0,0032 \mathrm{X}^{3}-$ $0,419 X^{2}+17,916 X-245,459, r^{2}=0,88, C V=27,07 \%$.

Figure 4. Water content of teguments (a), cotyledons (c) and embryonic axes (e) and water potential of teguments (b), cotyledons (d) and embryonic axes (f) of seeds of Paubrasilia echinata E.Gagnon, H.C.Lima \& G.P.Lewis obtained in Franca (O), São Paulo State, Brazil, during the development and maturation. Regressions $(\mathrm{p}<0.05): \mathrm{Y}_{(\mathrm{a})}=-0.0105 \mathrm{X}^{3}+1.384 \mathrm{X}^{2}-60.166 \mathrm{X}+934.205, \mathrm{r}^{2}=0.95, \mathrm{CV}=6.21 \% ; \mathrm{Y}$ (b) $-0.072 \mathrm{X}^{2}+4.702 \mathrm{X}+11.574, \mathrm{r}^{2}=0.98, \mathrm{CV}=4.64 \% ; \mathrm{Y}_{(\mathrm{c})}=-0.092 \mathrm{X}^{2}+7.392 \mathrm{X}-66.264, \mathrm{r}^{2}=0.74, \mathrm{CV}=13.56 \% ; \mathrm{Y}_{(\mathrm{d})}=0.023 \mathrm{X}^{2}-2.048 \mathrm{X}+44.850$, $\mathrm{r}^{2}=0.73, \mathrm{CV}=52.19 \% ; \mathrm{Y}_{(\mathrm{e})}=0.020 \mathrm{X}^{2}-1.727 \mathrm{X}+36.737, \mathrm{r}^{2}=0.89, \mathrm{CV}=36.23 \% ; \mathrm{Y}_{(\mathrm{f})}=0.0032 \mathrm{X}^{3}-0.419 \mathrm{X}^{2}+17.916 \mathrm{X}-245.459, \mathrm{r}^{2}=0.88$, $\mathrm{CV}=27.07 \%$. 
maturação (Marcos Filho 2015, Barbedo \& Santos Junior 2018). No entanto, a quantidade de água presente na semente não necessariamente representa o estado energético dessa água (Villela \& Marcos Filho 1998). De fato, no presente estudo, os resultados observados para potencial hídrico, tanto das sementes quanto dos frutos das populações avaliadas, não acompanharam a mesma tendência dos valores de teor de água durante as diferentes fases de desenvolvimento (figura 3 e tabela 2). Apesar do teor de água elevado das sementes no início da maturação, os potenciais hídricos foram, inicialmente, -6,9, -4,8 e -2,1 MPa para Franca, São Paulo e Santos, respectivamente. Portanto, para sementes de pau-brasil, durante o período de maturação, a grande quantidade de água no início do desenvolvimento não implica, necessariamente, em grande disponibilidade de água livre para a semente, talvez pelas constantes reações com diversos solutos durante a formação dessas sementes. Modificações nos potenciais hídricos das sementes, de valores menores no início da maturação em sentido a valores maiores entre os 40-50 DAA, indicam maior quantidade de água disponível para as reações metabólicas neste estádio de maturação, momento este que o teor de água nas sementes está também elevado, mas com valores ainda próximos ao observado no início da maturação (figura 3). Avançando na maturação, o potencial hídrico é reduzido, atingindo nos últimos estádios analisados os valores de -7,5, -4,6 e -3,1 MPa em Santos, São Paulo e Franca, respectivamente (figura 3 e tabela 2), acompanhando, concomitantemente, a acentuada dessecação das sementes na Fase III. Em São Paulo, sementes recém-dispersas que apresentavam $16,7 \%$ de água possuíam potencial hídrico extremamente baixo, -54,5 MPa. Em Franca, de uma forma geral, os potenciais hídricos dos tegumentos, cotilédones e eixos embrionários, no período analisado, demonstraram haver, inicialmente, menor disponibilidade hídrica, seguida por maior disponibilidade hídrica entre os 40-50 DAA e, novamente, a posterior redução até o final da maturação (figura 3). No entanto, a fase de maior disponibilidade hídrica para o eixo-embrionário ocorreu 5 dias após (4555 DAA) os outros dois tecidos. Estes tecidos também apresentaram, ao final do processo de maturação, menores valores de potencial hídrico, chegando a -9,7 MPa nos eixos embrionários. Nos frutos, nas populações de Franca e São Paulo os valores iniciais dos potenciais hídricos foram mais elevados que o das sementes, mas aos 40-50 DAA houve inversão nesta relação, que se manteve até o final do processo de maturação, ficando os frutos com valores menores que as sementes (figura 3). Essa inversão não foi observada na população de Santos, provavelmente por não se ter obtido frutos e sementes tão imaturos quanto os das outras duas populações.

Quanto mais negativo é o potencial hídrico em um sistema aquoso, menor será também a disponibilidade de água nesse sistema. Quando dois sistemas aquosos são separados por uma membrana permeável, ocorrerá sempre a migração da água do potencial hídrico mais elevado para o mais baixo, para o equilíbrio energético entre os sistemas (Larcher 2000, Castro et al. 2004). A inversão nos potenciais hídricos entre os frutos e sementes a partir dos 40-50 DAA, pode permitir a perda de água das sementes (figura 3 ), com base no princípio acima descrito, através da migração desta para os frutos de forma passiva, uma vez que ao apresentar potencial hídrico inferior à semente neste período, o fruto poderia absorver a água das sementes por diferenças no potencial hídrico.

O conteúdo de massa seca das sementes aumentou progressivamente do início ao final do processo de maturação, entretanto com valores finais bem distintos entre as 3 populações (figura 5 e tabela 2). Em Santos foram observadas, aos 60 DAA, sementes mais pesadas $(308,67 \mathrm{mg}$ semente $\left.^{-1}\right)$, seguidas por Franca $\left(236,25 \mathrm{mg} \mathrm{semente}^{-1}\right)$ e São Paulo (193,26 mg semente $\left.{ }^{-1}\right)$. Estas diferenças poderiam ser explicadas pelas condições ambientais durante a formação das sementes em cada região, como observado por Borges et al. (2005) para a produção das sementes em um mesmo local, mas em dois anos consecutivos. Daws et al. (2004) demonstraram influência no peso final de sementes de Aesculus hippocastanum em decorrência de mudanças no regime hídrico durante o período de sua formação. Estas variações podem estar relacionadas a mudanças na atividade fotossintética, como resultado da maior ou menor quantidade de água e desta forma, maior ou menor produção de assimilados (Larcher 2000).

O período de máximo acúmulo de massa seca verificado entre as três populações foi atingido entre os 60-65 DAA, momento que poderia ser definido como "ponto de maturidade de massa" (Ellis \& Pieta Filho 1992). No entanto, há autores que, apesar de concordarem com a importância deste momento no desenvolvimento da semente, não adotam uma terminologia específica para ele, mas definem o termo "ponto de maturidade fisiológica" no qual, além do máximo acúmulo de massa seca, outros parâmetros também importantes como, por exemplo, o máximo de germinabilidade e vigor das sementes, devem ser considerados como parâmetros para a identificação de sementes de excelente qualidade (Marcos Filho 2015, Silva et al. 2018, Guardia et al. 2018).

Sementes de pau-brasil são capazes de germinar já no início da Fase II (Kermode 1990, Marcos Filho 2015, Silva et al. 2018) de desenvolvimento (figura 6 e tabela 2), quando as sementes possuem menos de $1 / 3$ da massa seca final e apresentam alto teor de água. Desta forma, a germinação dessas sementes, que podem suportar secagem até $7 \%$ de água (Barbedo et al. 2002), ocorreu mesmo sem as sementes passarem pelo processo de secagem ao final da maturação, o qual é fundamental para muitas espécies com sementes classificadas como ortodoxas (Kermode 1990). Com 16\% de germinação aos 35 DAA, as sementes de Franca foram as primeiras a adquirirem germinabilidade. Em todas as populações, a germinação aumentou progressivamente 

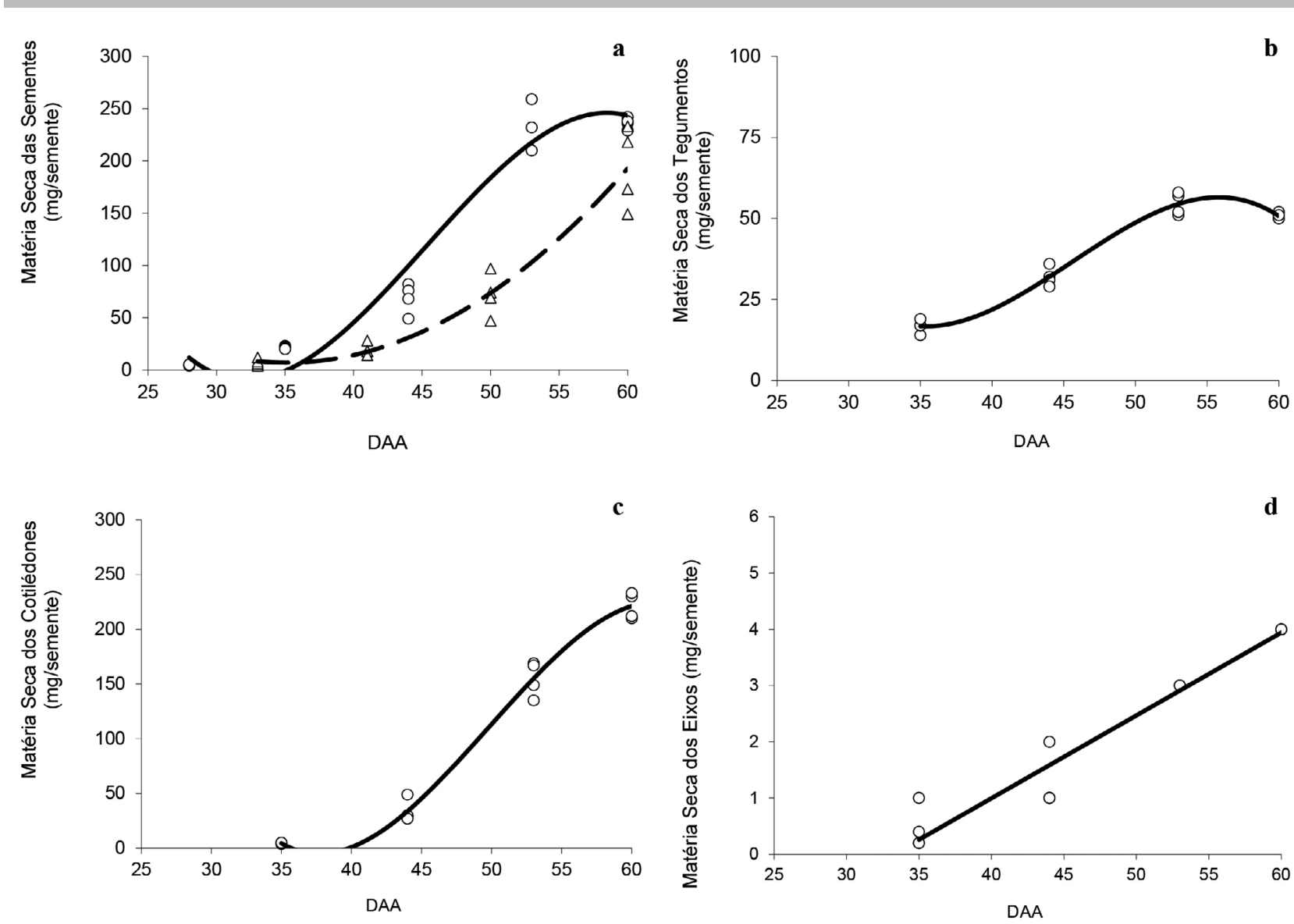

Figura 5. Conteúdo de massa seca de sementes de Paubrasilia echinata E.Gagnon, H.C.Lima \& G.P.Lewis durante o desenvolvimento e maturação: sementes íntegras (a) para Franca $(O$, linha cheia) e São Paulo ( $\triangle$, linha tracejada) e tegumentos (b), cotilédones (c) e eixos embrionários (d) para Franca $\left(\mathrm{O}\right.$, linha cheia), Estado de São Paulo, Brasil. Regressões $(\mathrm{p}<0,05)$ : $\mathrm{Y}_{\text {(a) }} \mathrm{O}=-0,028 \mathrm{X}^{3}+3,809 \mathrm{X}^{2}-$ $158,054 X+2065,930, r^{2}=0,95, C V=11,07 \% ; Y_{(a)} \triangle=0,299 X^{2}-20,972 X+374,775, r^{2}=0,93, C V=30,54 \% ; Y_{(b)}=-0,0094 X^{3}+1,283 X^{2}-$ $55,557 \mathrm{X}+791,911, \mathrm{r}^{2}=0,98, \mathrm{CV}=6,64 \% ; \mathrm{Y}_{(\mathrm{c})}=-0,033 \mathrm{X}^{3}+4,889 \mathrm{X}^{2}-229,092 \mathrm{X}+3437,221, \mathrm{r}^{2}=0,99, \mathrm{CV}=10,86 \% ; \mathrm{Y}_{(\mathrm{d})}=0,147 \mathrm{X}-4,896$, $\mathrm{r}^{2}=0,94, \mathrm{CV}=14,42 \%$.

Figure 5. Dry matter of seeds of Paubrasilia echinata E.Gagnon, H.C.Lima \& G.P.Lewis during development and maturation: entire seeds (a) from Franca $(O$, full line) and São Paulo $(\triangle$, dash line) and teguments $(b)$, cotyledons (c) and embryonic axes (d) from Franca ( $\mathrm{O}$, full line), São Paulo State, Brazil. Regressions $(\mathrm{p}<0.05)$ : $\mathrm{Y}_{(\mathrm{a})} \mathrm{O}=-0.028 \mathrm{X}^{3}+3.809 \mathrm{X}^{2}-158.054 \mathrm{X}+2065.930, \mathrm{r}^{2}=0.95, \mathrm{CV}=11.07 \%$; $\mathrm{Y}_{(\mathrm{a})} \triangle=0.299 \mathrm{X}^{2}-20.972 \mathrm{X}+374.775, \mathrm{r}^{2}=0.93, \mathrm{CV}=30.54 \% ; \mathrm{Y}_{(\mathrm{b})}^{(\mathrm{a})}=-0.0094 \mathrm{X}^{3}+1.283 \mathrm{X}^{2}-55.557 \mathrm{X}+791.911, \mathrm{r}^{2}=0.98, \mathrm{CV}=6.64 \% ; \mathrm{Y}_{(\mathrm{c})}=$ $-0.033 \mathrm{X}^{3}+4.889 \mathrm{X}^{2}-229.092 \mathrm{X}+3437.221, \mathrm{r}^{2}=0.99, \mathrm{CV}=10.86 \% ; \mathrm{Y}_{(\mathrm{d})}=0.147 \mathrm{X}-4.896, \mathrm{r}^{2}=0.94, \mathrm{CV}=14.42 \%$.

durante todo o processo de maturação, com valores máximos e muito próximos atingidos aos 58-60 DAA em Franca (94\%), 60 DAA em Santos (93\%) e por volta dos 60-65 DAA em São Paulo (90\%). Mesmo com altos valores de germinação obtidos, segundo Barbedo et al. (2002) e Borges et al. (2005) sementes de pau-brasil com elevado vigor atingem valores superiores a $95 \%$ de germinação.

Apesar da semente adquirir condições de germinar ainda muito cedo no processo de desenvolvimento, possivelmente as reservas acumuladas ainda sejam insuficientes para a produção de plântulas ou os processos metabólicos necessários para a formação da semente madura, ainda não estejam concluídos, pois plântulas com desenvolvimento normal foram verificadas, de uma forma geral nas três populações analisadas, somente a partir dos 50 DAA(figura 6 e tabela 2) e aumentou progressivamente, atingindo o máximo entre os 60-65 DAA de acordo com as regressões obtidas. Plântulas vigorosas foram verificadas apenas aos 60 DAA em São Paulo e Santos, com, em média, $46 \%$ e $67 \%$ de plântulas, respectivamente, momento este muito próximo à dispersão das sementes. Em Franca, estas foram verificadas já aos 53 DAA e aumentou até os 60 DAA, quando atingiu, em média, somente $41 \%$ (figura 6 ). Desta forma, apesar de valores consideravelmente altos de germinação que poderiam sugerir a elevada qualidade de um lote, as sementes de pau-brasil das populações avaliadas, apresentaram baixa produção de plântulas com alto vigor. Quando as sementes adquirem a capacidade germinativa e nos momentos seguintes a esta, a velocidade de germinação ainda é bastante baixa e aumentará somente 

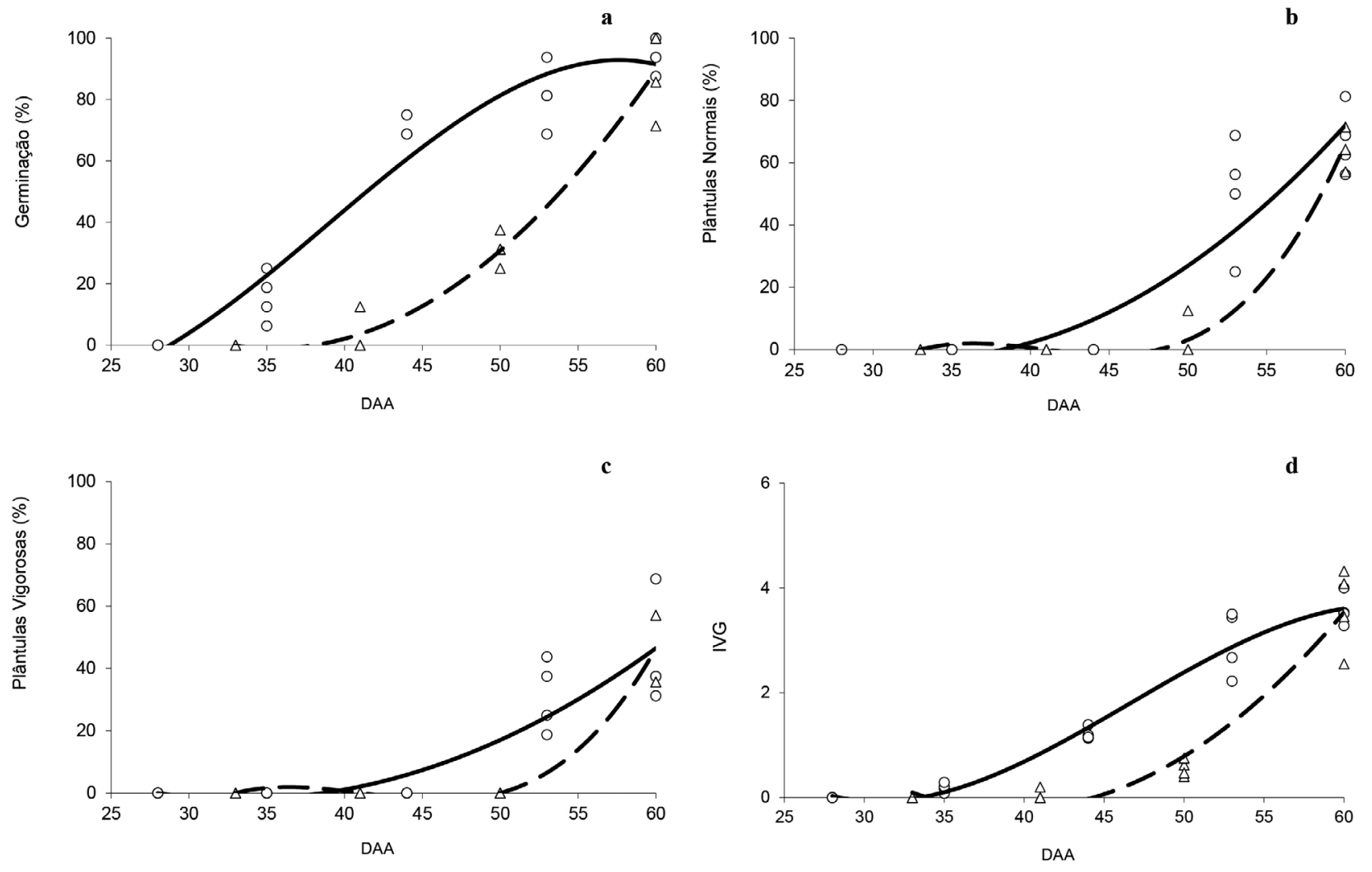

Figura 6. Germinação (a), plântulas com desenvolvimento normal (b), plântulas vigorosas (c) e índice de velocidade de germinação (d) para sementes de Paubrasilia echinata E.Gagnon, H.C.Lima \& G.P.Lewis obtidas nos municípios de Franca $(O$, linha cheia) e São Paulo $(\triangle$, linha tracejada), Estado de São Paulo, Brasil, durante o desenvolvimento e maturação. Regressões $(p<0,05): Y_{(a)} O=-0,0041 X^{3}+0,477 X^{2}-$ $14,285 \mathrm{X}+113,164, \mathrm{r}^{2}=0,95, \mathrm{CV}=12,27 \% ; \mathrm{Y}_{\text {(a) }} \triangle=0,149 \mathrm{X}^{2}-10,554 \mathrm{X}+185,707, \mathrm{r}^{2}=0,96, \mathrm{CV}=26,16 \% ; \mathrm{Y}_{(\mathrm{b})} \mathrm{O}=0,102 \mathrm{X}^{2}-6,701 \mathrm{X}+107,420$, $\mathrm{r}^{2}=0,87, \mathrm{CV}=40,81 \% ; \mathrm{Y}_{(\mathrm{b})} \triangle=0,011 \mathrm{X}^{3}-1,305 \mathrm{X}^{2}+52,458 \mathrm{X}-694,613, \mathrm{r}^{2}=0,98, \mathrm{CV}=27,06 \% ; \mathrm{Y}_{(\mathrm{c})} \mathrm{O}=0,068 \mathrm{X}^{2}-4,537 \mathrm{X}+73,489, \mathrm{r}^{2}=$ $0,80, \mathrm{CV}=60,77 \% ; \mathrm{Y}_{(\mathrm{c})} \triangle \stackrel{\mathrm{(b)}}{=} 0,009 \mathrm{X}^{3-1} 1,124 \mathrm{X}^{2}+45,802 \mathrm{X}-613,202, \mathrm{r}^{2}=0,93, \mathrm{CV}=52,15 \% ; \mathrm{Y}_{(\mathrm{d})} \mathrm{O}=-0,0002 \mathrm{X}^{3}+0,033 \mathrm{X}^{2}-1,387 \mathrm{X}+17,820$, $\mathrm{r}^{2}=0,96, \mathrm{CV}=19,87 \% ; \mathrm{Y}_{\text {(d) }} \triangle=0,0087 \mathrm{X}^{2}-0,678 \mathrm{X}+13,042, \mathrm{r}^{2}=0,93, \mathrm{CV}=38,57 \%$.

Figure 6. Germination (a), normal seedling growth (b), strong seedling (c) and germination speed index (d) of seeds of Paubrasilia echinata E.Gagnon, H.C.Lima \& G.P.Lewis obtained in Franca $(\mathrm{O}$, full line) and São Paulo ( $\triangle$, dash line), São Paulo State, Brazil, during the development and maturation. Regressions $(\mathrm{p}<0.05)$ : $\mathrm{Y}_{\text {(a) }} \mathrm{O}=-0.0041 \mathrm{X}^{3}+0.477 \mathrm{X}^{2}-14.285 \mathrm{X}+113.164, \mathrm{r}^{2}=0.95, \mathrm{CV}=12.27 \%$; $\mathrm{Y}_{(\mathrm{a})} \triangle=0.149 \mathrm{X}^{2}-10.554 \mathrm{X}+185.707, \mathrm{r}^{2}=0.96, \mathrm{CV}=26.16 \% ; \mathrm{Y}_{\text {(b) }} \mathrm{O}=0.102 \mathrm{X}^{2}-6.701 \mathrm{X}+107.420, \mathrm{r}^{2}=0.87, \mathrm{CV}=40.81 \% ; \mathrm{Y}$ (b) $\triangle=$ $0.011 \mathrm{X}^{3}-1.305 \mathrm{X}^{2}+52.458 \mathrm{X}-694.613, \mathrm{r}^{2}=0.98, \mathrm{CV}=27.06 \% ; \mathrm{Y}_{(\mathrm{c})} \mathrm{O}=0.068 \mathrm{X}^{2}-4.537 \mathrm{X}+73.489, \mathrm{r}^{2}=0.80, \mathrm{CV}=60.77 \% ; \mathrm{Y}(\mathrm{c}) \triangle=0.009$ $\mathrm{X}^{3-1} 1.124 \mathrm{X}^{2}+45.802 \mathrm{X}-613.202, \mathrm{r}^{2}=0.93, \mathrm{CV}=52.15 \% ; \mathrm{Y}_{(\mathrm{d})} \mathrm{O}=-0.0002 \mathrm{X}^{3}+0.033 \mathrm{X}^{2}-1.387 \mathrm{X}+17.820, \mathrm{r}^{2}=0.96, \mathrm{CV}=19.87 \% ; \mathrm{Y}(\mathrm{d})$ $0.0087 \mathrm{X}^{2}-0.678 \mathrm{X}+13.042, \mathrm{r}^{2}=0.93, \mathrm{CV}=38.57 \%$.

momentos antes da dispersão (figura 6 e tabela 2). Nas populações de Franca e de São Paulo foi verificado o mesmo valor máximo de IVG $(3,60)$, enquanto que na de Santos, mesmo produzindo as sementes mais pesadas e com potenciais germinativos e de produção de plântulas semelhantes aos das outras duas populações, apresentou IVG inferior $(2,88)$.

Os resultados obtidos neste estudo para matéria seca, germinação e produção de plântulas normais ou vigorosas, sugerem que a maturidade fisiológica para as sementes de pau-brasil, nas populações avaliadas no Estado de São Paulo, ocorre ao redor dos 60-65 DAA, momento próximo à dispersão natural das sementes pelos frutos. Este curto período entre a maturidade fisiológica e a dispersão é crítico para a obtenção de sementes com elevada qualidade fisiológica, afetando diretamente o vigor, importante para a inclusão das sementes desta importante espécie, sob risco de extinção, em bancos de germoplasma (Barbedo et al. 2002, Rocha et al. 2014). Adicionalmente, a presença de manchas castanhas ou a total pigmentação dos frutos por esta cor, bem como o enrijecimento dos acúleos, ocorre concomitantemente aos 60-65 DAA, quando as sementes apresentam teor de água ao redor de $30-40 \%$. Estas características podem, portanto, auxiliar na identificação do melhor ponto de colheita de sementes de pau-brasil nas populações avaliadas neste estudo. 
Os resultados do presente trabalho e os obtidos por Borges et al. (2005), para plantas de pau-brasil de populações localizadas em diferentes regiões do Estado de São Paulo, com expressivas variações de latitude $\left(20^{\circ} \mathrm{S}\right.$ a $\left.24^{\circ} \mathrm{S}\right)$ e de altitude ( 0 a 900 metros), demonstram variações no início do florescimento dentro de um intervalo de aproximadamente 60 dias, entre a segunda quinzena de agosto e primeira quinzena de outubro. No entanto, foi constatada que a maturação de frutos e sementes de pau-brasil apresentou, de forma geral, comportamento padrão, mesmo em condições ambientais diferentes, inclusive com a dispersão ocorrendo entre 65-70 dias após a antese das flores em todas as regiões estudadas.

Finalizando, três interessantes e importantes aspectos podem ser destacados: o primeiro, a precocidade na aquisição da capacidade germinativa, aos 30-40 DAA, ou seja, próximo à metade do ciclo total; o segundo, a tardia aquisição da capacidade de produção de plântulas normais, ou seja, no final do processo de maturação, ao redor dos 60-65 DAA. Assim, apesar da semente adquirir a capacidade de germinar muito cedo, esta característica é ineficaz na identificação de sementes maduras pois, possivelmente, as reservas acumuladas ainda são insuficientes ou não ocorreram todas as reações metabólicas necessárias para a completa maturação da semente, impedindo assim o desenvolvimento de plântulas e o estabelecimento do indivíduo; e o terceiro, em relação ao interessante e essencial controle da movimentação de água entre frutos e sementes, ora regulando o fluxo em direção às sementes, garantindo a continuidade do acúmulo de reservas, ora em direção ao fruto, permitindo eficiente desidratação das sementes no momento em que um grau de umidade mais elevado tornaria o ambiente favorável a uma rápida deterioração das mesmas.

\section{Agradecimentos}

Ao Jardim Botânico Municipal "Chico Mendes", ao Jardim Zoobotânico de Franca e ao Jardim Botânico de São Paulo, pela permissão e suporte para as coletas; ao Programa de Pós-Graduação em Biodiversidade Vegetal e Meio Ambiente, pela oportunidade de desenvolver este trabalho como parte da Dissertação de Mestrado do primeiro Autor; à Fundação de Amparo à Pesquisa do Estado de São Paulo (FAPESP) pelo apoio financeiro ao projeto (00/06422-4).

\section{Literatura citada}

Angyalossy, V., Amano, E. \& Alves, E.S. 2005. Madeiras utilizadas na fabricação de arcos para instrumentos de corda: aspectos anatômicos. Acta Botânica Brasileira 19: 819-834.

Barbedo, C.J. 2018. A new approach towards the so-called recalcitrant seeds. Journal of Seed Science 40: 221-236.
Barbedo, C.J. \& Santos Junior, N.A. 2018. Sementes do Brasil: produção e tecnologia para espécies da flora brasileira. Instituto de Botânica, São Paulo.

Barbedo, C.J., Bilia, D.A.C. \& Figueiredo-Ribeiro, R.C.L. 2002. Tolerância à dessecação e armazenamento de sementes de Caesalpinia echinata Lam. (pau-brasil), espécie da Mata Atlântica. Revista Brasileira de Botânica 25: 431-439.

Barbedo, C.J., Centeno, D.C. \& Figueiredo-Ribeiro, R.C.L. 2013. Do recalcitrant seeds really exist? Hoehnea 40: 583-593.

Borges, I.F., Giudice Neto, J.D., Bilia, D.A.C., FigueiredoRibeiro, R.C.L. \& Barbedo, C.J. 2005. Maturation of seeds of Caesalpinia echinata Lam. (brazilwood), an endangered leguminous tree from the Brazilian Atlantic Forest. Brazilian Archives of Biology and Technology 48: 851-861.

Brasil. 2009. Regras para análise de sementes. Ministério da Agricultura, Pecuária e Abastecimento, Secretaria de Defesa Agropecuária, Brasília.

Castro, R.D., Bradford, K.J. \& Hilhorst, H.W.M. 2004. Desenvolvimento de sementes e conteúdo de água. In A.G. Ferreira \& F. Borghetti (eds.). Germinação: do básico ao aplicado. Porto Alegre: Artmed, pp. 51-67.

Cunha, M.W. \& Lima, H.C. 1992. Viagem à terra do paubrasil. Agência Brasileira de Cultura, Rio de Janeiro.

Daws, M.I., Lydall, E., Chmielarz, P., Leprince, O., Matthews, C.A., Thanos, C.A. \& Pritchard, H.W. 2004. Developmental heat sum influences recalcitrant seed traits in Aesculus hippocastanum across Europe. New Phytologist 162: 157-166.

Decagon. 2001. WP4 Dewpoint PotentiaMeter Operator's Manual. Decagon Devices, Inc., Pullman.

Ellis, R.H. \& Pieta Filho, C. 1992. Seed development and cereal seed longevity. Seed Science Research 2: 9-15.

Figueiredo-Ribeiro, R.C.L., Barbedo, C.J., Alves, E.S., Domingos, M. \& Braga, M.R. 2008. Pau-brasil, da semente à madeira: conhecer para conservar. Instituto de Botânica, São Paulo.

Gagnon, E., Bruneau, A., Hughes, C.E., Queiroz, L.P. \& Lewis, G.P. 2016. A new generic system for the pantropical Caesalpinia group (Leguminosae). PhytoKeys 71: 1-60.

Gomes, F.P. 1982. Curso de estatística experimental. $10^{\mathrm{a}}$ ed. Nobel, Piracicaba.

Guardia, M.C., Asperti, L.M., Fidalgo, A.O. \& Garcia, V.A. 2018. Produção e obtenção de sementes. In: C.J. Barbedo \& N.A. Santos Junior (orgs.). Sementes do Brasil: produção e tecnologia para espécies da flora brasileira. São Paulo: Instituto de Botânica, pp. 41-62.

Kermode, A.R. 1990. Regulatory mechanisms involved in the transition from seed development to germination. Critical Reviews in Plant Sciences 9: 155-195. 
Larcher, W. 2000. Ecofisiologia Vegetal. Rima, São Carlos.

Lewis, G.P. 1998. Caesalpinia: a revision of the PoincianellaErythrostemon group. Royal Botanic Gardens, Kew.

Maguire, J.D. 1962. Speed of germination-aid in selection and evaluation for seedling emergence vigor. Crop Science 2: 176-177.

Marcos Filho, J. 2015. Fisiologia de sementes de plantas cultivadas. 2.ed. ABRATES, Londrina.

Mello, J.I.O. \& Barbedo, C.J. 2007. Temperatura, luz e substrato para germinação de sementes de paubrasil (Caesalpinia echinata Lam., Leguminosae Caesalpinioideae). Revista Árvore 31: 645-655.

Mello, J.I.O., Figueiredo-Ribeiro, R.C.L. \& Barbedo, C.J. 2013. Sub-zero temperature enables storage of seeds of Caesalpinia echinata Lam. Journal of Seed Science 35: 519-523.

Rocha, Y.T., Lamarca, E.V., Simabukuro, E.A., Barbedo, C.J., Domingos, M., \& Figueiredo-Ribeiro, R.C.L. 2014. Propuesta de una red de áreas protegidas para la protección del pau-brasil (Caesalpinia echinata Lam. - Leguminosae), árbol del bosque atlántico litoral. In: Artigas, R.C., Pérez, B.R. \& Gómez, J.L.M. (eds.) Biogeografía de sistemas litorales. Dinámica y conservación. Sevilla: Universidad de Sevilla, pp. 103108.

Santana, D.G. \& Ranal, M.A. 2004. Análise da germinação: um enfoque estatístico. Editora UnB, Brasília.
Santos, M.R.O. \& Barbedo, C.J. 2017. Deterioration rates of brazilwood seeds (Caesalpinia echinata Lam.), under high temperatures. Hoehnea 44: 449-463.

Silva, J.P.N., Centeno, D.C., Figueiredo-Ribeiro, R.C.L. \& Barbedo, C.J. 2015. Maturation of seeds of Poincianella pluviosa (Caesalpinoideae). Journal of Seed Science 37: 131-138.

Silva, E.E.A., Oliveira, J.M. \& Pereira, W.V.S. 2018. Fisiologia das sementes. In: C.J. Barbedo \& N.A. Santos Junior (orgs.). Sementes do Brasil: produção e tecnologia para espécies da flora brasileira. São Paulo: Instituto de Botânica, pp. 15-40.

Steel, R.G.D \& Torrie, J.H. 1980. Principles and procedures of statistics. $2^{\mathrm{a}}$ ed. McGraw Hill, New York.

Summerfield, R.J., Ellis, R.H., Craufurd, P.Q., Aiming, Q., Roberts, E.H. \& Wheeler, T.R. 1997. Environmental and genetic regulation of flowering of tropical annual crops. Euphytica 96: 83-91.

Taiz L. \& Zeiger, E. 2004. Fisiologia Vegetal. 3.ed. Porto Alegre, Artmed.

Teixeira, S.P., Carmello-Guerreiro, S.M. \& Machado, S.R. 2004. Fruit and seed ontogeny related to the seed behavior of two tropical species of Caesalpinia (Leguminosae). Botanical Journal of the Linnean Society 146: 57-70.

Villela, F.A. \& Marcos Filho, J. 1998. Estados energéticos e tipos de água na semente. Revista Brasileira de Sementes 20: 317-321. 